\title{
Gastric cancer and other endoscopic diagnoses in patients with benign dyspepsia
} N P Breslin, A B R Thomson, R J Bailey, P K Blustein, J Meddings, E Lalor,
G M A VanRosendaal, M J Verhoef, L R Sutherland diagnosis of dyspepsia includes duodenal ulcer, gastric ulcer, non-ulcer dyspepsia, gastrooesophageal reflux, and gastric cancer. Helicobacter pylori plays a causative role in the vast majority of non-NSAID (non-steroidal antiinflammatory drug) gastric and duodenal ulcers and may also be important in a subgroup of patients with non-ulcer dyspepsia. ${ }^{4-7}$ Fifty four per cent of dyspeptic patients are under the age of 45 years. $^{8}$

The relation between $H$ pylori and diseases of the upper gastrointestinal tract and our ability to diagnose the infection by serology or urea breath test has led to the concept of initial noninvasive screening for $H$ pylori in young dyspeptic subjects without sinister symptoms (weight loss, dysphagia, gastrointestinal bleeding, or anaemia). ${ }^{9-11}$ Many community physicians are treating patients on the basis of such tests. ${ }^{12}$ Referral for endoscopy may be reserved for those with persisting, recurrent, or altered symptoms or at the discretion of the responsible physician.

The apparent low incidence of gastric cancer in subjects under 45 years of age in the absence of sinister symptoms is often cited as a reason why such strategies are safe. ${ }^{13}$ In one study comprising 618 patients who underwent either endoscopy $(n=271)$ or barium meal $(n=347)$ there were no gastric cancers detected. The authors also reported that gastric malignancy in those less than 45 years of age accounted for $1.8 \%$ of all gastric malignancies in a six year period. All of these patients had sinister symptoms at presentation. In another study, 24 of 25 patients under 55 years of age developing gastric cancer had at least one suspicious symptom. ${ }^{14}$ A further study, reported in abstract form, reviewed a local cancer registry and found that five of 68 patients under 55 years with gastric cancer presented without sinister symptoms. However, four of these had unresectable disease. The authors concluded that the presentation of upper gastrointestinal malignancy in this subgroup was uncommon and usually at an advanced stage. ${ }^{15}$ The primary aim of our study was to examine the validity of this assumption in a large population of young patients who had undergone an endoscopy for the investigation of apparently "benign dyspepsia". The secondary aim was to describe other endoscopic diagnoses in this population of patients that might alter management beyond helicobacter eradication or empirical antisecretory therapy.

Abbreviations used in this paper: NSAID, non-steroidal anti-inflammatory drug.
Community Health Sciences,

University of Calgary, 3330

Hospital Dr NW, Alberta

T2N 4N1, Canada

Accepted for publication 21 July 1999
Dyspepsia affects $30-40 \%$ of adults over meriod, accounting for $2-3 \%$ of prim care consultations and approximately $40 \%$ of referrals to gastroenterologists. ${ }^{12}$ Endoscopy is the gold standard investigation for dyspepsia. One in 200 people undergo a gastroscopy each year in the United Kingdom. ${ }^{3}$ The differential 


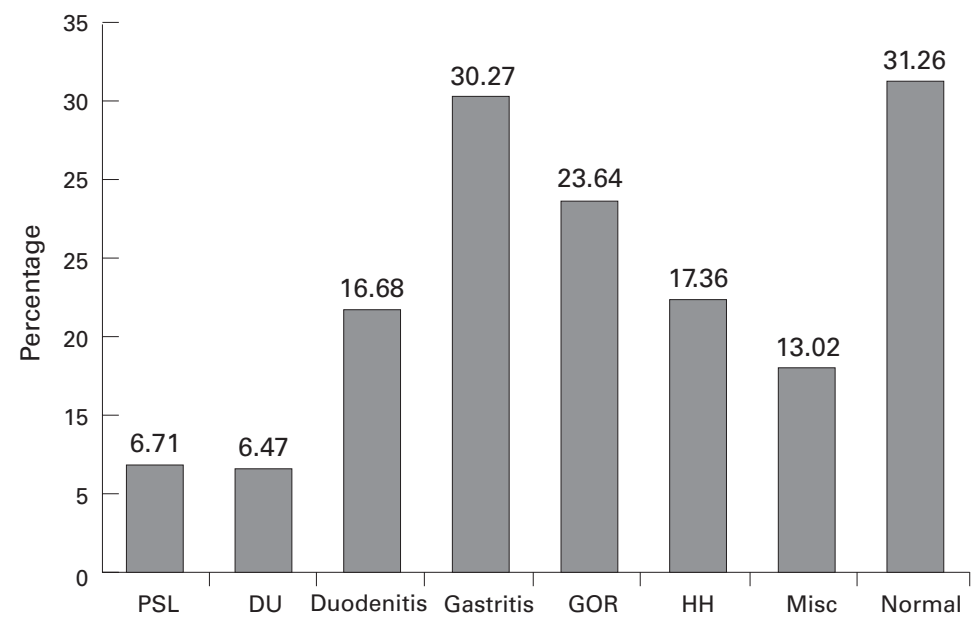

Figure 1 Proportion of patients with specific diagnoses. Actual percentages are given above bars. Note that a given patient could have more than one diagnosis. PSL, potentially significant lesion (gastric ulcer, possible neoplasm, oesophageal stricture, varices, or Barrett's oesophagus); DU, duodenal ulcer; GOR, gastro-oesophageal reflux; HH, hiatus hernia.

\section{Methods}

The Alberta Endoscopy Project captured clinical and demographic data on all upper and lower gastrointestinal endoscopies performed from April 1993 to February 1996 at four major adult hospitals in Alberta, Canada. During this time approximately one per hundred of the study population underwent an endoscopy each year (personal communication, Alberta Healthcare Insurance Plan). Approval for this study was obtained from the Conjoint Medical Ethics Committee of the University of Calgary. Data entered included patient name, date of birth, sex, procedure date, indications for the procedure (three fields allowed), and macroscopic findings at endoscopy (four fields allowed). The data were analysed using the statistics program SAS System, version 6.12 (SAS Institute Inc., Cary, North Carolina, USA). The database was searched to identify adult patients who were less than 45 years old at the time of the procedure and in whom the indications for endoscopy included abdominal pain, reflux symptoms, or nausea. Where patients had undergone more than one procedure, only the first one was considered. Patients were excluded if there was a history of diarrhoea, NSAID use, gastric surgery, or sinister symptoms (weight loss, dysphagia, odynophagia, haematemesis, melaena, anaemia, or previous gastric surgery).

Prior to the review a number of recorded diagnoses were designated to be likely to alter patient management. These included patients in whom the endoscopic appearances suggested gastric cancer, gastric ulcer, varices, Barrett's oesophagus, or oesophageal stricture/ ring. The health records for all of these patients were requested for review to confirm inclusion criteria and recorded macroscopic findings, and to review confirmatory histological evidence.

To assess the accuracy of the database search for "benign dyspepsia" and suitability of patients for a non-invasive management strategy, a random list of 200 charts (50 from each of the four participating hospitals) was gener- ated. The records of these 200 patients were reviewed by one of the investigators (NPB) to determine whether other symptoms or conditions were present which would bias the physician towards performing endoscopy. This included those with sinister symptoms, postsurgical stomach, NSAID use, those whose symptoms necessitated admission to hospital, and patients with complicating conditions such as Crohn's disease. The proportion of these subjects fitting the criteria for benign dyspepsia-termed "correction factor"-was multiplied by the total number of patients with this recorded diagnosis registered in the databank to give an estimate of the true sample size.

\section{STUDY DESIGN}

The study was a cross sectional study. All patients meeting the entry criteria as specified above were considered for the study with the exception of those for whom data recording was incomplete. Data were analysed using basic descriptive statistics; $\chi^{2}$ analysis was used to compare categorical characteristics between groups.

\section{Results}

The database contained complete data including age, indications for, and findings at upper gastrointestinal endoscopy in 20331 individuals (total number of procedures $=26114$ ), 7004 of whom were under 45 years of age. Exclusion of those with sinister symptoms or other disqualifying characteristics yielded 3634 subjects $(56 \%$ females) with apparently "benign dyspepsia". Among this group the endoscopy was normal in 1136 (31.3\%, confidence interval (CI) 29.8-32.8\%). There were 244 patients in the benign dyspepsia group with endoscopic diagnoses that might alter future management. Among this group there were 20 patients with a lesion suggestive of a gastric neoplasm, 94 patients with a gastric ulcer, 12 patients with oesophageal varices, 74 patients with an oesophageal stricture, and 55 patients with an apparent Barrett's oesophagus. Some patients had more than one diagnosis. Figure 1 summarises the endoscopic findings for the 3634 patients considered.

The health records of 231 of the 244 patients with "significant lesions" were available for review. Table 1 summarises the findings. After careful review of case records 176 patients had symptoms that could be classified as nonsinister and amenable to an initial non-invasive approach. Two of the 20 patients with suspicious lesions were found to have a gastric cancer on review of biopsy samples. At surgery, patient 1 , aged 35 years, was found to have disease extending through the stomach wall; the patient underwent a partial gastrectomy and remains disease free at five years' follow up. Patient 2, aged 34 years, was found to have advanced disease with liver metastases. In the group of patients with gastric ulcer there was one patient, aged 38 years, with early gastric cancer who underwent curative resection. Prior to endoscopy none of these patients was noted to have risk factors for gastric cancer such as 
Table 1 Outcome of patients with diagnoses that might favour an initial invasive approach-"significant diagnoses"

\begin{tabular}{llllll}
\hline & $\begin{array}{l}\text { Suspicious } \\
\text { lesion }\end{array}$ & Gastric ulcer & Varices & $\begin{array}{l}\text { Suspected Barrett's } \\
\text { oesophagus }\end{array}$ & Stricture \\
\hline Include & $\begin{array}{l}15 \text { cases } \\
2 \text { gastric } \\
\text { cancers }\end{array}$ & $\begin{array}{l}63 \text { cases } \\
\text { cancer } \\
\text { cantric }\end{array}$ & No cases & 46 cases & 19 cases \\
& & $\begin{array}{l}1 \text { moderate } \\
\text { dysplasia }\end{array}$ & & & 16 oesophageal ring \\
Revised diagnosis & - & - & - & - & 3 benign stricture \\
Exclude & 3 & 26 & 11 & 5 & 44 reflux/hiatus \\
$\begin{array}{l}\text { Record unavailable } \\
\text { Total }\end{array}$ & 2 & 5 & 1 & 4 & 9 \\
\hline & 20 & 94 & 12 & 55 & 2 \\
\hline
\end{tabular}

Patients were excluded if their presenting symptoms on case record review were considered sinister or where other illnesses precluded a non-invasive approach.

pernicious anaemia, previous gastric surgery, or a positive family history. The presence of $H$ pylori was not commented on in histological reports in any of these three patients, and other diagnostic tests for the bacterium were not performed. An additional patient in the gastric ulcer group had histological changes consistent with moderate dysplasia. In this patient successful eradication of $H$ pylori resulted in apparent reversal of these changes.

In the subgroup defined as having benign dyspepsia, 94 individuals were identified as having a gastric ulcer. Case records were available in 89 patients of whom 63 would have been suitable for non-invasive management. Those excluded were as follows: postsurgical stomach, seven; NSAID use, seven; sinister symptoms not recorded in database, two; acute presentation requiring admission, two; incorrect diagnosis, two; and complicating medical illnesses, four.

In those patients with an apparent oesophageal stricture/ring an asymptomatic oesophageal ring was noted in 16 cases and benign oesophageal narrowing in three. In 44 cases the

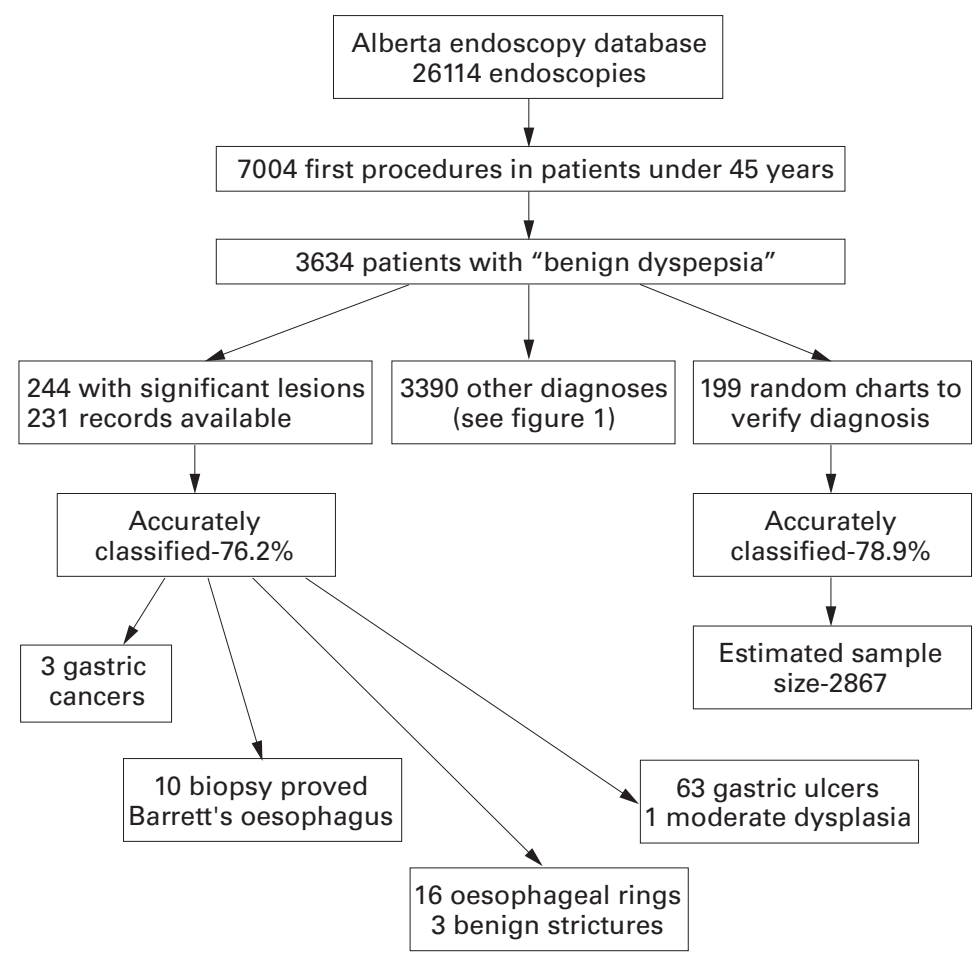

Figure 2 Summary of study methods and results.
Table 2 Reasons for excluding patients from category of benign dyspepsia, based on review of 199 random charts

\begin{tabular}{lc}
\hline Reason for exclusion & No of patients \\
\hline Crohn's disease & 8 \\
Postsurgical stomach & 7 \\
NSAID use & 7 \\
Diarrhoea & 4 \\
Weight loss & 3 \\
Haematemesis/melaena & 2 \\
Anaemia & 2 \\
Acute admission & 2 \\
Liver disease & 1 \\
Other & 6 \\
Total & 42
\end{tabular}

NSAID, non-steroidal anti-inflammatory drug.

chart recorded diagnosis was gastrooesophageal reflux disease and/or hiatus hernia. In no case was dilatation performed and there were no cases of oesophageal cancer. In the remainder, patient symptoms or underlying disease precluded their inclusion as benign dyspepsia. In 11 of the 12 cases of oesophageal varices the patient had a history of significant underlying liver disease and therefore would have been unsuitable for a non-invasive strategy. The case record was unavailable for review in the remaining patient. Barrett's oesophagus was suspected endoscopically in 55 patients. Ten patients had histologically proved changes without evidence of dysplasia.

In total 199 of the 200 patient health records generated at random to assess the accuracy of the diagnosis of benign dyspepsia were available for review. Forty two patients $(21.1 \%$, CI $15.7-27.4 \%$ ) were found to have other symptoms/conditions not recorded in the database which would have precluded an initial non-invasive approach to their investigation (table 2). Therefore, $78.9 \%$ of subjects were suitable for a non-invasive management strategy, yielding a correction factor for our total sample of 0.789 . When the charts of the 244 patients with apparently significant diagnoses were reviewed, a similar proportion of individuals with disqualifying characteristics was found $(23.8 \%, \mathrm{p}=0.5)$. The unadjusted prevalence of gastric cancer in the sample was three in 3634 patients. Using the correction factor of 0.789 patients with benign dyspepsia in our sample, we arrived at a new denominator of 2867 for the three cases of gastric cancer and calculate the prevalence of gastric cancer to be 1.05 per 1000 patients under 45 years old with apparently benign dyspepsia. Figure 2 provides an overall summary of the study.

\section{Discussion}

This cross sectional study suggests a prevalence of one gastric cancer per thousand young patients with apparently benign dyspepsia who are referred for specialist management. If one considers only resectable lesions, the prevalence falls to less than one per thousand.

The impact of delaying the diagnosis of gastric cancer by giving a short course of empirical therapy is unknown. ${ }^{16} \mathrm{~A}$ strategy of treating those found to be helicobacter positive with one week triple therapy followed by early assessment of symptom response is unlikely to affect outcome significantly. Indeed, it can be 
argued that one week of triple therapy is preferable to continuous empirical acid suppression therapy as it is unlikely to mask symptoms of more serious pathology for any longer than the short duration of therapy.

Apart from the study of Williams et $a l,{ }^{13}$ our paper is the first to report on the occurrence of gastric cancer in a large series of patients under 45 years of age undergoing endoscopy for the investigation of benign dyspepsia. The small sample size and use of barium studies (which may have missed early lesions) in over $50 \%$ of their patients may have compromised their negative study. In contrast to their study we found three patients with gastric cancer and one with moderate dysplasia presenting with apparently benign dyspepsia. Gastric cancer does occur in patients with non-sinister dyspeptic symptoms. However, the chance of finding a gastric cancer is low and in excess of 1000 endoscopies would need to be performed in young patients with benign dyspepsia to detect one resectable gastric cancer. In our health region the cost of an endoscopy is $\$ 560$ (Canadian)-excluding the cost of processing of histological specimens or indirect costs such as loss of time from work. Therefore, the cost of diagnosing one resectable gastric cancer in this subgroup would be in excess of $\$ 800000$. The cost-benefit ratio of this requires further exploration.

Sixty three patients with presenting symptoms amenable to a non-invasive management strategy had gastric ulcer. This represents $2.4 \%$ of those with benign type symptoms and raises an important issue. Traditionally it has been recommended that all patients with gastric ulcer should have multiple biopsy specimens taken from the ulcer margin at the initial procedure and undergo repeat endoscopy with biopsy until healing has occurred to rule out occult malignancy ${ }^{17-26}$ However, the yield from such a practice has been questioned and many of the cancers in these patients develop several years after the index ulcer, often in a different site and in an older age group. ${ }^{27-31}$ In our study none of the patients with gastric ulcer was found to have gastric cancer during follow up. It is possible that patients with benign presenting symptoms and gastric ulcer represent a lower risk group in this regard, although this remains unproved. However, this issue requires exploration in the context of non-invasive strategies and in the broader context of repeat endoscopy.

In the present study oesophageal stricture/ ring was a recorded diagnosis in 74 cases. The clinical significance of these lesions was not clear from the database. Case record review revealed 16 oesophageal rings and three benign strictures. In no case was oesophageal dilatation performed. In nine individuals presenting features precluded an initial non-invasive approach. In the remainder, endoscopic reflux and/or a large hiatus hernia were invariably present. The impact of endoscopy on outcome in patients with benign strictures or rings is uncertain. ${ }^{32-34}$ In addition, there is evidence that in patients with reflux symptoms, endoscopy results in increased drug prescribing and the use of more expensive drugs. ${ }^{35}$
It can be argued that endoscopy would have significantly altered management in 106 of the 2867 young persons undergoing this investigation for benign dyspepsia (three gastric cancers, 93 gastric ulcers, and 10 cases of histologically proved Barrett's oesophagus). This represents $3.7 \%$ of our sample and questions the role of endoscopy in the initial management of such patients, where for the majority empirical acid suppression therapy or Helicobacter pylori eradication may have provided a similar end result.

However, in many patients with dyspeptic symptoms, whether young or old, the fear of an underlying malignancy is a significant issue. ${ }^{36}$ There is evidence that endoscopy provides significant reassurance for many of these patients $^{37}$ and may also have a therapeutic benefit. ${ }^{38} 39$ The reassurance provided by a non-invasive test for $H$ pylori might be expected to be less effective. However, in the study of Patel et al the proportion of patients expressing reassurance after serological testing for investigation of dyspepsia was similar to that in a cohort who underwent endoscopy. ${ }^{11}$

This study has a number of limitations. Firstly, it is retrospective and the database was not designed specifically for the evaluation of benign dyspepsia. Nonetheless, we have endeavoured to address this by the detailed assessment of 200 charts drawn at random and found the computer assigned diagnosis to be reliable in approximately $80 \%$ of cases. This finding is confirmed in our review of the health records of the 231 patients with apparently significant lesions. Secondly, the endoscopist entered the data after the procedure was performed. Therefore, we cannot exclude the possibility of the endoscopic findings biasing the symptoms recorded by the physician. Thirdly, all patients were referred for specialist management. Thus the sample is biased and the findings cannot necessarily be extrapolated to community dyspeptic subjects. Fourthly, the possibility of additional early gastric cancers cannot be ruled out among those patients who were recorded as having gastritis. The majority of these did not have mucosal biopsies. Finally, assessment for $H$ pylori was performed in only a minority of patients and therefore potential outcomes of screening strategies could not be evaluated in the context of this study.

In conclusion, the prevalence of operable gastric cancer in benign dyspepsia as defined in this study is less than one in a thousand. A one week course of eradication therapy for $H$ pylori positive subjects is unlikely to result in a significant delay in diagnosis and treatment of such lesions. However, the clinician must be aware that gastric cancer may present in this subgroup of patients at a potentially curable stage. Overall, endoscopy would have significantly altered management beyond empirical strategies in less than $4 \%$ of those studied. A strategy of initial non-invasive management is unlikely to have a negative impact in the majority of young patients with benign dyspepsia as long as the physician is aware of potential significant underlying diagnoses and arranges endoscopy where appropriate. 
Dr N Breslin is a recipient of the Searle, Canada Research Fellowship. The Alberta Endoscopy Project was funded by Alberta Health. We are indebted to Ms Vicki Stagg for her expertise in analysis of the computer database.

1 Knill-Jones RP. Geographical differences in the prevalence of dyspepsia. Scand $\mathcal{f}$ Gastroenterol 1991;182(suppl): 17-24.
2 Jones R, Lydeard S. Dyspepsia in the community: a Jones R, Lydeard S. Dyspepsia in the com
follow-up study. Br $\mathcal{F}$ Clin Pract 1992;46:95-7.

3 British Society of Gastroenterology. Provision of gastrointestinal endoscopy and related services for a district general hospital. London: BSG, 1990.

4 Graham DY, Lew GM, Klein PD, et al. Effect of treatment of Helicobacter pylori infection on the long-term recurrence of gastric or duodenal ulcer. A randomized, controlled study. Ann Intern Med 1992;116:705-8.

5 Seppala K, Pikkarainen P, Sipponen P, et al. Cure of peptic gastric ulcer associated with eradication of Helicobacter pylori. Finnish Gastric Ulcer Study Group. Gut 1995;36: pylori.

6 Kuipers EJ, Thijs JC, Festen HMP. The prevalence of Helicobacter pylori in peptic ulcer disease. Aliment Pharmacol Ther 1995;9:59-69.

7 McCarthy C, Patchett S, Collins RM, et al. Long-term prospective study of Helicobacter pylori in nonulcer dyspepsia. Dig Dis Sci 1995;40:114-19.

8 Penston JG, Pounder RE. A survey of dyspepsia in Great Britain. Aliment Pharmacol Ther 1996;10:83-9.

9 Sobala GM, Crabtree JE, Pentith JA, et al. Screening dyspepsia by serology to Helicobacter pylori. Lancet 1991; 338:94-6.

10 Mendall MA, Jazrawi RP, Marrero JM, et al. Serology for Helicobacter pylori compared with symptom questionnaires in screening before direct access endoscopy. Gut 1995;36:330-3.

11 Patel P, Khulusi S, Mendall MA, et al. Prospective screening of dyspeptic patients by Helicobacter pylori serology. Lancet 1995;346:1315-18.

12 Penston JG, Mistry KR. Eradication of Helicobacter pylori in general practice. Aliment Pharmacol Ther 1996;10:139in gent

13 Williams B, Luckas M, Ellingham JH, et al. Do young patients with dyspepsia need investigation? Lancet 1988;ii: patients with $1349-51$.

14 Christie J, Shepherd NA, Codling BW, et al. Gastric cancer below the age of 55: implications for screening patients with uncomplicated dyspepsia. Gut 1997;41:513-17.

15 Gillen D, McColl KE. Uncomplicated dyspepsia is a very rare presentation of gastric cancer under age 55 [abstract]. Gastroenterology 1996;110:A519.

16 Silverstein MD, Petterson T, Talley NJ. Initial endoscopy or empirical therapy with or without testing for Helicobacter pylori for dyspepsia: a decision analysis. Gastroenterology
1996;110:72-83.

17 Sakita T, Oguro Y, Takasu S, et al. Observations on the healing of ulcerations in early gastric cancer. The life cycle of the malignant ulcer. Gastroenterology 1971;60:835-9.

18 Paulino F, Roselli A. Early gastric cancer: report of twentyfive cases. Surgery 1979;85:171-6.

19 Mountford RA, Brown P, Salmon PR, et al. Gastric cancer detection in gastric ulcer disease. Gut 1980;21:9-17.
20 Haukland HH, Johnson JA, Eide JT. Carcinoma diagnosed in excised gastric ulcers. Acta Chir Scand 1981;147:439-43.

21 Farinati F, Cardin F, Di Mario F, et al. Early and advanced gastric cancer during follow-up of apparently benign gastric ulcer: significance of the presence of epithelial dysplasia. F Surg Oncol 1987;36:263-7.

22 Paustian FF, Stein GN, Young JF, et al. The importance of a brief trial of rigid medical management in the diagnosis of bastroenterology 1960;38:155-64.

23 Larson NE, Cain JC, Bartholomew LG. Prognosis of medically treated small ulcer. $N$ Engl f Med 1961;264:119-23.

24 Maaroos HI, Salupere V, Uibo R. Gastric ulcer, gastritis and gastric carcinoma. Ann Clin Res 1981;13:151-3.

25 Dekker W, Tytgat GN. Diagnostic accuracy of fiberendoscopy in the detection of upper intestinal malignancy. A follow-up analysis. Gastroenterology 1977;73:710-14.

26 Bytzer P. Endoscopic follow-up study of gastric ulcer to detect malignancy: is it worthwhile? Scand $\mathcal{f}$ Gastroenterol 1991;26:1193-9.

27 Pruitt RE, Truss CD. Endoscopy, gastric ulcer, and gastric cancer. Follow-up endoscopy for all gastric ulcers? Dig Dis Sci 1993;38:284-8.

28 Tragardh B, Haglund U. Endoscopic diagnosis of gastric ulcer. Evaluation of the benefits of endoscopic follow-up observation for malignancy. Acta Chir Scand 1985;151:3741.

29 Rollag A, Jacobsen CD. Gastric ulcer and risk of cancer. A five-year follow-up study. Acta Med Scand 1984;216:105-9.

30 Lee S, Iida M, Yao T, et al. Long-term follow-up of 2529 patients reveals gastric ulcers rarely become malignant. Dig Dis Sci 1990;35:763-8.

31 Jorde R, Bostad L, Burhol PG. Asymptomatic gastric ulcer: a follow-up study in patients with previous gastric ulcer disease. Lancet 1986;i:119-21.

32 Jones DB, Smith PM. Conservative management of benign oesophageal strictures. Endoscopy 1981;13:55-6.

33 Wesdorp IC, Bartelsman JF, den Hartog J, et al. Results of conservative treatment of benign esophageal strictures: a follow-up study in 100 patients. Gastroenterology 1982;82: 487-93.

34 Patterson DJ, Graham DY, Smith JL, et al. Natural history of benign esophageal stricture treated by dilatation. Gastroenterology 1983;85:346-50.

35 Ellis KK, Oehlke M, Helfand M, Lieberman D. Management of symptoms of gastroesophageal reflux disease: does endoscopy influence medical management? Am f Gastroenterol 1997;92:1472-4.

36 Johannessen T, Petersen H, Kleveland PM, et al. The predictive value of history in dyspepsia. Scand $\mathcal{F}$ Gastroenpredictive value of hist

37 Bytzer P, Hansen JM, Schaffalitzky DMO. Empirical H2-blocker therapy or prompt endoscopy in management of dyspepsia. Lancet 1994;343:811-16

38 Lydeard S, Jones R. Factors affecting the decision to consult with dyspepsia: comparison of consulters and nonconsulters. $\mathcal{F}$ R Coll Gen Pract 1989;39:495-8.

39 Jones R. What happens to patients with non-ulcer dyspepsia after endoscopy? Practitioner 1988;232:75-6. 